\author{
REGULAR ARTICLE
}

\title{
ESTIMATION OF MORPHOLOGICAL AND MOLECULAR GENETIC DIVERSITY IN BLACKGRAM [VIGNA MUNGO (L.) HEPPER] UNDER YMV HOTSPOT REGIME
}

\section{S. JEEVITHA, R. KARTHIKEYAN, M. VIGNESH, A. MALARKODI, R. TIRUMALAI, A. J. NAINU, R. ANANDAN, M. PRAKASH, S. MURUGAN*}

Department of Genetics and Plant Breeding, Faculty of Agriculture, Annamalai University, Annamalai Nagar 608002, Tamilnadu, India

\begin{abstract}
A phenotypic and molecular diversity study was conducted using seven traits and 19 SSR markers in a collection of 26 black gram genotypes. Phenotypic characterization was based on seven yield and yield related variable. The field experiment was laid out at Panboli village (YMV hotspot) of Tirunelveli District in Tamilnadu during summer 2017. Genetic divergence was estimated on the basis of $\mathrm{D}^{2}$ values and 26 genotypes under study were grouped into six clusters by Tocher's method. Seed yield per plant followed by Plant height and number of pods per plant contributed to the genetic divergence. The genetic distance announced using DICE dissimilarity co-efficient indicated highest divergence of 1.o between VBN 8 and AUBG 17 and between VBN 8 and AUBG 19. The dendogram constructed using the DICE dissimilarity co-efficient between genotypes showed four apparent clusters based on marker allele distribution. Divergence was noted between the dissimilarity matrices based on the molecular and phenotypic diversity based on agronomic data.
\end{abstract}

Keywords: Genetic diversity, YMV, SSR markers

\section{INTRODUCTION}

Pulses are one among the important crops in the world. They are grown on 21-22 million hectares of area globally with an annual production of 12-16 million tonnes [1]. Among the pulses, pigeon pea, blackgram and greengram are the major contributors of the total pulses production. Blackgram or urad bean belongs to the family Leguminaceae and the genus Vigna. Consideration of genetic diversity existing in a population is the basic requirement for effective improvement programme [2]. Hence an attempt was made to assess the phenotypic diversity using morphological traits and to estimate genetic diversity of blackgram accessions using molecular markers.

\section{MATERIALS AND METHODS}

\section{Plant materials}

A set of twenty six black gram genotypes were used in the present investigation. Of these, twenty genotypes were cultures (AUBG-1, AUBG-2, AUBG-3, AUBG-4, AUBG-5, AUBG-6, AUBG-7, AUBG-8, AUBG-9, AUBG-10, AUBG-11, AUBG-12, AUBG-13, AUBG-14, AUBG-15, AUBG-16, AUBG-17, AUBG-18, AUBG-19 and AUBG-20) developed in Department of Genetics and Plant Breeding, Annamalai University and six were commercial cultivars (VBN-3, VBN-4, VBN-5, VBN-6, VBN-7 and VBN-8) obtained from
National Pulses Research Centre, Vamban, Pudukkottai district, Tamil Nadu, India. Genetically pure seeds of each accession were raised in experimental field of Department of Genetics and Plant Breeding, Faculty of Agriculture, Annamalai University, Tamil Nadu, India.

\section{Molecular markers}

A total of 19 microsatellite markers proved to be polymorphic and linked with YMV resistance in black gram and mung bean were selected from previously published literatures [3-5]. The markers were CEDG 008, CEDG 011, CEDG 013, CEDG 014. CEDG 020, CEDG 022, CEDG 030, CEDG 044, CEDG 056, CEDG 059, CEDG 067, CEDG 092, CEDG 133, CEDG 198, YMV 1, YR 4, CYR 1, CEDG 180.

\section{Sample preparation}

The genomic DNA was isolated from leaf tissue of $20 \mathrm{~d}$ old seedlings following the standard protocol [6].

\section{PCR amplification}

PCR was conducted in a thermocycler (Mastercycler Personal, Eppendorf, USA).). The amplification reaction consisted of an initial denaturation at $94{ }^{\circ} \mathrm{C}$ for $4 \mathrm{~min}$ followed by 40 cycles of $1 \mathrm{~min}$ at $94{ }^{\circ} \mathrm{C}, 1 \mathrm{~min}$ at $50-62{ }^{\circ} \mathrm{C}$ (depending on marker type), and $1 \mathrm{~min}$ at $72{ }^{\circ} \mathrm{C}$ and finally terminated with an extension of $7 \mathrm{~min}$ at $72{ }^{\circ} \mathrm{C}$. List of SSR

\section{Received 17 March 2018; Accepted 11 April 2018 \\ *Corresponding Author \\ S. Murugan}

Department of Genetics and Plant Breeding, Faculty of Agriculture, Annamalai University, Annamalai Nagar 608002, Tamilnadu, India

Email: agriman2001@yahoo.com

( This article is open access and licensed under the terms of the Creative Commons Attribution License (http://creativecommons.org/licenses/by/4.o/) which permits unrestricted, use, distribution and reproduction in any medium, or format for any purpose, even commercially provided the work is properly cited. Attribution - You must give appropriate credit, provide a link to the license, and indicate if changes were made. 
markers and their annealing temperatures are given in table 2 . The amplified PCR products $(10 \mu \mathrm{l})$ were resolved on $1.5 \%$ $(\mathrm{w} / \mathrm{v})$ agarose gels in $1 \mathrm{X}$ TBE buffer. The gel was stained with ethidium bromide as previously described. The size of the fragments was estimated using a $100 \mathrm{bp}$ ladder (Genei, Bangalore) as a size marker. The gel was run till the dye reached the end of the gel, then the gel images were photographed using Gel Documentation system (Vilber Lourmat, France). All the PCR reactions were repeated thrice to ensure reproducibility and reliability of the results.

\section{Data analysis}

The amplified DNA fragments in gel images were transformed to binary data $(0,1)$, where 1 and 0 were scored for presence and absence of alleles, respectively. Percent polymorphism for each marker was generated by the formula: (Number of polymorphic alleles/Total number of alleles) x 100. The clustering was done by using the dissimilarity coefficient matrix for the twenty six genotypes by employing the unweighted neighbour joining method bootsraped over 5000 times. The clads showing more than $70 \%$ of the bootstrap value were considered arbitrarily as a strong cluster. Cluster analysis was performed using the neighbor-joining (NJ) method with the DARwin v. 5.0.157 software [7].

\section{Field experiment for phenotypic variability}

Twenty six genotypes of black gram were evaluated for seven yield and yield attributing traits viz., Plant height, number of branches per plant, number of clusters per plant, number of pods per plant, pod length, number of seeds per pod, seed yield per plant. The genotypes were grown in the YMV hotspot, Panboli village of Tirunelveli District, Tamil Nadu during summer, 2017. Thee genotypes were sown in single row with spacing of $30 \mathrm{X} 10 \mathrm{~cm}$ in two replications. The quantum of genetic divergence was also assessed by cluster analysis using Mahalanobis's euclidean squares distances which grouped the entire material into more precise clusters and estimates the average distance between them.

\section{RESULTS AND DISCUSSION}

The dendogram constructed using the DICE dissimilarity co-efficient between genotypes showed four apparent clusters based on marker allele distribution. The first cluster consisted of six genotypes (AUBG 2, AUBG 7, AUBG 9, AUBG 12, AUBG 13 and AUBG 16) and accommodated 23\% of the total population based on allelic similarity. The second cluster consisted of four genotypes having a membership density of $\mathbf{1 5 . 4 \%}$. It consisted of AUBG 3, AUBG 4, AUBG 10 and AUBG 11. The third cluster consisted of eight genotypes accommodating 30.8\% of total genotypes. It consisted of all VBN genotypes VBN 3, VBN 4 , VBN 5 , VBN 6, VBN 7, and VBN 8 along with AUBG 18 and AUBG 20. The fourth cluster had remaining $27 \%$ of the population consisting of genotypes AUBG 5, AUBG 6, AUBG 8, AUBG 14, AUBG 15, AUBG 17 and AUBG 9 (Fig.1).
The quantum of genetic divergence was also assessed by cluster analysis using Mahalanobis's euclidean squares distances which grouped the entire material into more precise clusters and estimates the average distance between them. Genetic divergence was estimated on the basis of D2 value and 26 genotypes under study were grouped into six clusters by Tocher's method as presented in table 1 and fig. 2. Cluster VI was the largest with 12 genotypes, AUBG7, AUBG8, AUBG9, AUBG12, AUBG13, AUBG14, AUBG15, AUBG17, AUBG18, $\mathrm{VBN}_{3}, \mathrm{VBN}_{5}$ and VBN8. Cluster I with 5 AUBG1, AUBG2, AUBG3, AUBG4 and AUBG16 was the second largest cluster. Cluster IV was the third largest cluster with 3 genotypes namely AUBG5, AUBG10, VBN4. The remaining clusters II, III and IV had two genotypes each.

The average intra and inter cluster $\mathrm{D}^{2}$ values are presented in table 2. Intra cluster values ranged from 12.86 (Cluster II) to 1188.15 (Cluster V). From the inter cluster values of six clusters, it can be seen that the highest divergence occured between cluster IV and cluster V (1591.36) followed by cluster V and cluster VI (1578.54), cluster II and cluster V (1554.80), cluster 1 and cluster V (1186.67) in that order of magnitude. The minimum inter cluster distance was noticed between cluster III and cluster IV (130.24)) followed by cluster II and cluster IV (104.92) and cluster II and cluster III (51.12).

In the present study there was a divergence in phenotypic and molecular genotypic diversity. The phenotypic diversity analysis produced six clusters while the molecular diversity analysis produced three clusters. All the VBN genotypes (developed in National Pulses Research Centre,Vamban, Tamilnadu) were in same cluster (cluster 3) by molecular diversity while they were in three different clusters by phenotypic diversity. Similarly the genotypes AUBG 5 and AUBG 10, AUBG 19 AND AUBG 11 which was grouped in the same cluster by phenotypic analysis were in different clusters by genotypic analysis. There were instances of correlation between both analysis. The genetic distance announced by DICE dissimilarity co-efficient indicated the lowest value of 0.007 between AUBG12 with AUBG13 and AUBG 16, and VBN5 with VBN6. This was in correlation with phenotypic diversity analysis were AUBG 12 and AUBG 13 were grouped in the same cluster. The highest divergence of 1.0 was between VBN8 and AUBG17 and between VBN8 and AUBG19. In the phenotypic analysis too VBN 8 and VBN 19 were grouped in different clusters.

Although the genotypes were subjected to natural hotspot condition for Yellow mosaic virus resistance the phenotypic clustering pattern didn't correlate with the genotypic clustering with SSR primers specific for YMV resistance in most of the occasions. Many studies have found less relationships between molecular genotypic analysis and genetic distances estimated from morphological data [8-14]. 


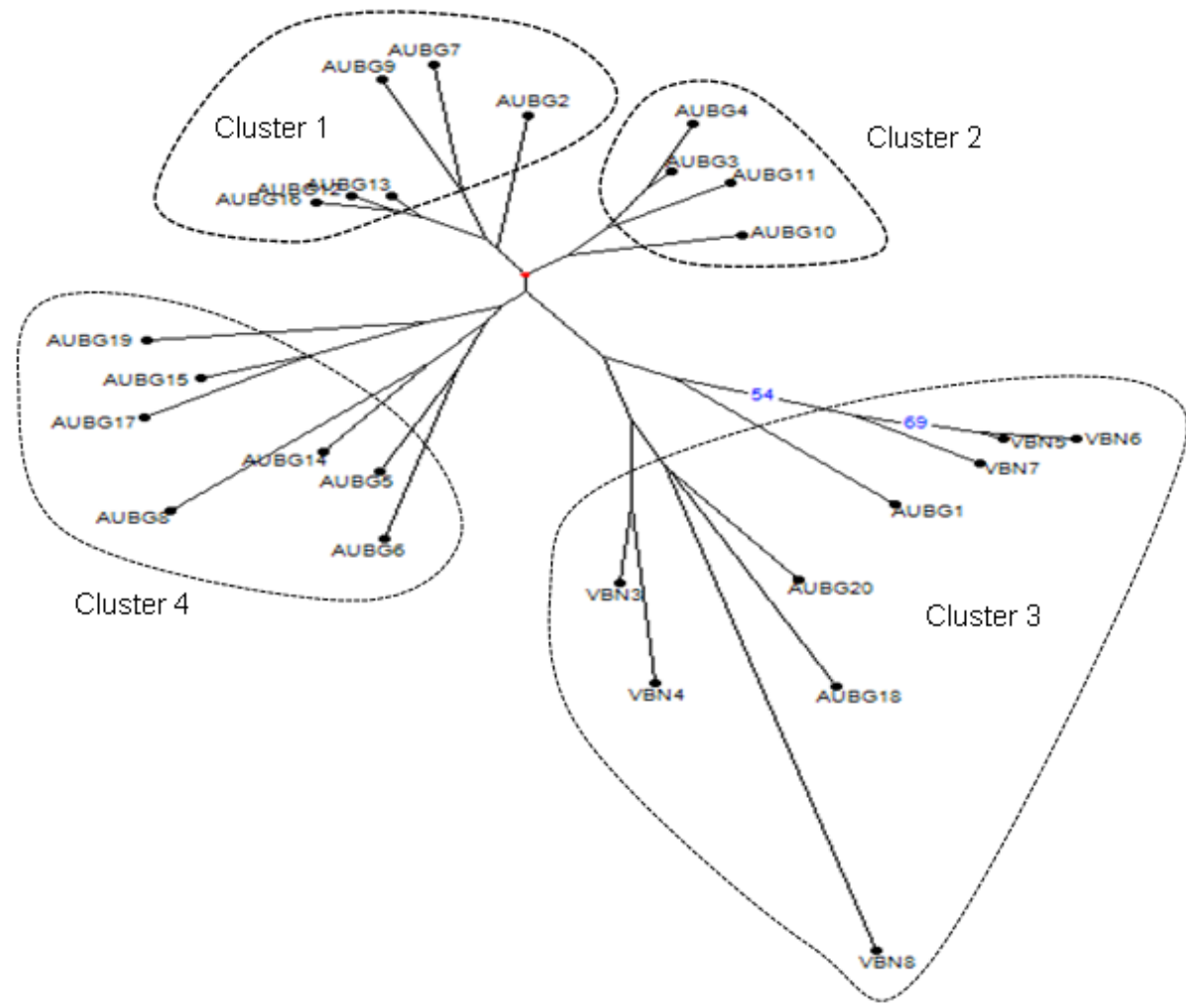

Fig. 1: Clustering of genotypes based on DICE dissimilarity coefficient

\begin{tabular}{ll}
\hline Cluster1 & 0.230769 \\
Cluster2 & 0.153846 \\
Cluster3 & 0.307692 \\
Cluster4 & 0.269231 \\
\hline
\end{tabular}

Although the neighbor joining procedure was bootstrapped 10000 times none of the clusters or clads showed bootstrap value more than $70 \%$. The highest bootstrap value of $69 \%$ was shown by two genotypes VBN5 and VBN6 followed by their grouping with VBN7 (54\%).

Table 1: Number of clusters and their varietal composition in blackgram

\begin{tabular}{lll}
\hline Clusters & $\begin{array}{l}\text { Number of } \\
\text { genotypes }\end{array}$ & Number of the genotypes \\
\hline Clusters I & 5 & AUBG-1, AUBG-2, AUBG-3, AUBG-4, AUBG-16 \\
Clusters II & 2 & VBN-6, VBN-7 \\
Clusters III & 2 & AUBG-6, AUBG-20 \\
Clusters IV & 2 & AUBG-11, AUBG-19 \\
Clusters V & 3 & AUBG-5, AUBG-10, VBN-4 \\
Clusters VI & 12 & $\begin{array}{l}\text { AUBG-7, AUBG-8, AUBG-9, AUBG-12, AUBG-13, AUBG-14, AUBG-15, AUBG-17, AUBG- } \\
18, \text { VBN-3, VBN-5, VBN-8 }\end{array}$ \\
\hline
\end{tabular}

Table 2: Average intra-cluster (bold) and inter-cluster D2values of blackgram

\begin{tabular}{|c|c|c|c|c|c|c|}
\hline Clusters & ClusterI & ClusterII & ClusterIII & ClusterIV & ClusterV & ClusterVI \\
\hline ClusterI & 261.938 & 184.093 & 182.379 & 277.009 & 1186.669 & 288.925 \\
\hline & $(16.184))$ & 13.568 & 13.505 & 16.644 & 34.448 & 16.998 \\
\hline ClusterII & & 12.86 & 130.237 & 104.918 & 1554.805 & 163.160 \\
\hline & & $(3.580)$ & 12.773 & 11.412 & 10.243 & 39.431 \\
\hline ClusterIII & & & 13.496 & 100.031 & 1061.323 & 227.850 \\
\hline & & & (3.674) & 10.002 & 32.578 & 15.095 \\
\hline ClusterIV & & & & 31.325 & 1591.363 & 187.826 \\
\hline & & & & $(5.597)$ & 39.892 & 13.705 \\
\hline ClusterV & & & & & 1188.147 & 1578.539 \\
\hline ClusterVI & & & & & $(34.470)$ & $\begin{array}{l}39.731 \\
281.365 \\
(16.774)\end{array}$ \\
\hline
\end{tabular}




\section{REFERENCES}

1. FAOSTAT. 2014.

2. V. Arunachalam Genetic distance in Plant breeding. Indian J. Genet. 41:226-236 (1981).

3. Souframanien J, Gopalakrishna T (2006) ISSR and SCAR markers linked to the mungbean yellow mosaic virus (MYMV) resistance gene in blackgram [Vigna amungo (L.) Hepper]. Plant Breed 125:619-622.

4. Maiti S, Basak J, Kundagrami S, Kundu A, Pal A (2011) Molecular marker-assisted genotyping of mungbean yellow mosaic India virus resistant germplasms of mungbean and urdbean. Mol Biotech 47:95-104.

5. Gupta S, Gupta DS, Anjum TK, Pratap A, Kumar J (2013) Transferability of simple sequence repeat markers in blackgram. Aust J Agric Sci (in press).

6. Doyle JJ, Doyle JL (1990) Isolation of plant DNA from fresh tissue. Focus 12:13-15.

7. Perrier X. and Jacquemoud-Collet JP. (2006) DARwin Software. http://darwin. cirad. fr/darwin.

8. Gepts, P. 1993. The use of molecular and biochemical markers in crop evolution studies. Evol. Biol. 27:5194.
9. Bretting PK, and Widrlechner MP 1995. Genetic markers and plant genetic resource management. Plant Breed. Rev. 13:11-71.

10. Karp A, Kresovich S, Bhat KV, Ayada WG, Hodgkin T, 1997. Molecular tools in plant genetic resources conservation: a guide to the technologies. IPGRI Technical Bulletin No.2. International Plant Genetic Resources Institute, Rome, Italy.

11. Lewontin RC. Detecting population differences in quantitative characters as opposed to genefrequencies. Am Nat. 1984;123:115-124.

12. Reed DH, Frankham R. How closely correlated are molecular and quantitative measures of genetic variation? A meta-analysis. Evolution. 2001;55:10951103.

13. Koehler-Santos P, Dornelles ALC, de Freitas LB. Characterization of mandarin citrus germplasm from southern Brazil by morphological and molecular analyses. Pesqui Agropecu Bras. 2003;38:797-806.

14. Martins FA, Carneiro PCS, da Silva DJH, Cruz CD, Carneiro JED. Integration of data in studies of genetic diversity of tomato. Pesqui Agropecu Bras. 2011: 46:1496-1502. 